\title{
Controlled surface ordering of endohedral fullerenes with a $\mathrm{SrTiO}_{3}$ template
}

\author{
David S Deak, Fabien Silly, Kyriakos Porfyrakis and \\ Martin R Castell \\ Department of Materials, University of Oxford, Parks Road, Oxford OX1 3PH, UK \\ E-mail: martin.castell@materials.ox.ac.uk
}

Received 9 October 2006, in final form 10 December 2006

Published 18 January 2007

Online at stacks.iop.org/Nano/18/075301

\begin{abstract}
The ability to select the way in which atoms and molecules self-organize on a surface is important for synthesizing nanometre scale devices. Here we show how endohedral fullerenes $\left(\mathrm{Er}_{3} \mathrm{~N} @ \mathrm{C}_{80}\right)$ can be assembled into four distinctive arrangements on a strontium titanate surface template. Each template pattern correlates to a particular reconstruction on n-doped $\mathrm{SrTiO}_{3}(001)$, made in whole or in part by self-assembled arrays of non-stoichiometric oxide nanostructures. Close-packed assemblies of $\mathrm{Er}_{3} \mathrm{~N} @ \mathrm{C}_{80}$ molecules are formed, as well as one-dimensional chains and two-dimensional grids. This method of template-assisted molecular ordering provides a new platform for the development of experimental schemes of classical and quantum information processing at the molecular level.
\end{abstract}

(Some figures in this article are in colour only in the electronic version)

\section{Introduction}

The technical realization of molecular-based devices will demand new methods of manufacturing that are likely to employ self-assembly techniques [1-4]. There is also the requirement for molecular systems to make explicit use of quantum mechanical effects. This holds true for molecular information processing systems that employ conventional classical logic functions [5, 6], and it is intrinsic for solidstate quantum information processing (QIP) [7] schemes. To meet these demands, it is necessary to have the ability to self-assemble functional molecular units, like endohedral fullerenes $[8,9]$, into useful assemblies such as cellular arrays [10-13].

Endohedral fullerenes are thought to be viable components for a variety of molecular electronic technologies [10-15]. A promising molecule to begin addressing these challenges is the exotic $\operatorname{Er}_{3} \mathrm{~N} @ \mathrm{C}_{80}$ molecule [16], shown in figure 1(a). This molecule has advantages over other endohedral fullerenes $[12,13]\left(\right.$ e.g. $\mathrm{N} @ \mathrm{C}_{60}$ ) in that $\mathrm{M}_{3} \mathrm{~N} @ \mathrm{C}_{80}$ species ( $\mathrm{M}$ is a metal in a planar $\mathrm{M}_{3} \mathrm{~N}$ unit) are thermally stable $[17,18]$ and can be evaporated onto heated substrates in ultrahigh vacuum (UHV). In addition, the magneto-optical activity [19] of the planar $\mathrm{Er}_{3} \mathrm{~N}$ unit in the $\mathrm{C}_{80}$ cage (figure 1(a)) may prove useful for QIP [20] and other applications. Challenges of im- plementing such schemes rely on the ability to assemble wellorganized arrays of useful endohedral fullerenes on suitable substrates.

Self-organized assemblies of fullerenes on surface templates have been demonstrated before [21-24]. These methods involve an initial step of pre-assembling molecular templates on metal or metal-terminated substrates, prior to deposition of fullerenes onto the template. In this paper we report a novel approach to organizing endohedral fullerene molecules, namely $\mathrm{Er}_{3} \mathrm{~N} @ \mathrm{C}_{80}$, into four different configurations on an oxide crystal template. This is achieved by using four variations of non-stoichiometric, nanostructured $\mathrm{SrTiO}_{3}(001)$ surfaces [25]. $\mathrm{SrTiO}_{3}$ is a high- $\kappa$ material, and this may in addition be of benefit for some applications, such as molecular field effect transistors [26-28] and solid-state QIP $[10,11]$.

\section{Experimental details}

The template evolves from 0.5 wt $\%$ Nb-doped $\mathrm{SrTiO}_{3}(001)$ single crystal samples, supplied by PI-KEM Ltd UK. Samples are $2 \times 7 \times 0.5 \mathrm{~mm}^{3}$ in size, with a conductivity of $\sim 1.4 \times$ $10^{4} \Omega^{-1} \mathrm{~m}^{-1}$ at room temperature prior to sample treatment. After introducing the samples into a JEOL UHV scanning tunnelling microscope (STM), model JSTM 4500s, they were 

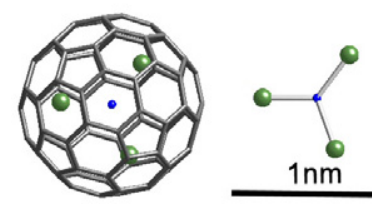

C

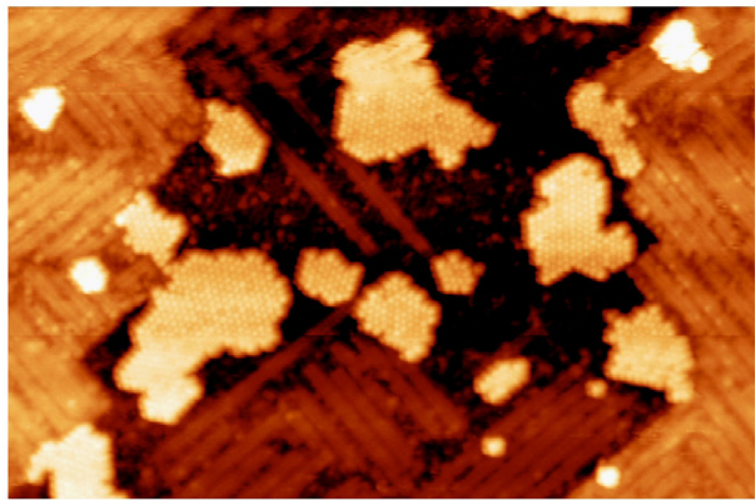

d

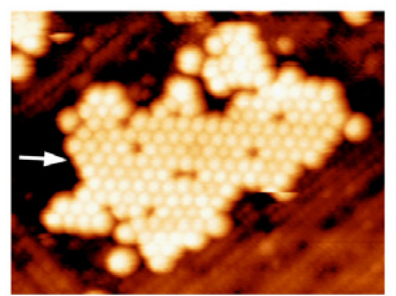

e
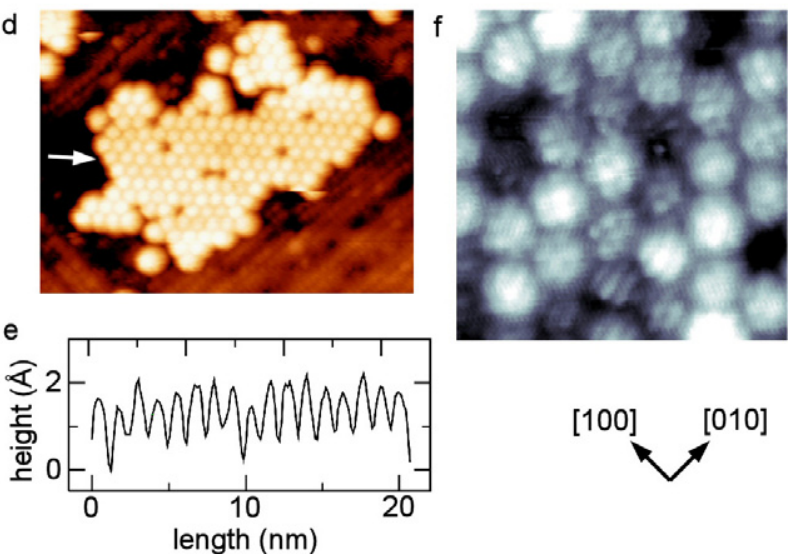

[100]

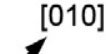

Figure 1. Non-epitaxial close-packed ordering on a $\mathrm{c}(4 \times 2)$ reconstructed surface. (a) $\mathrm{The} \mathrm{Er}_{3} \mathrm{~N} @ \mathrm{C}_{80}$ molecule and the $\mathrm{Er}_{3} \mathrm{~N}$ unit without the cage ( $\mathrm{N}$ at the centre). STM images of: (b) a template based on a $\mathrm{c}(4 \times 2)$ reconstruction with a diline structure $\left(16 \times 15 \mathrm{~nm}^{2} ; V_{\mathrm{s}}=+1.0 \mathrm{~V} ; I_{\mathrm{t}}=0.07 \mathrm{nA}\right),(\mathrm{c}) \mathrm{Er}_{3} \mathrm{~N} @ \mathrm{C}_{80}$ molecule islands on the $\mathrm{c}(4 \times 2)$ terraces $\left(120 \times 80 \mathrm{~nm}^{2} ; V_{\mathrm{s}}=+2.2 \mathrm{~V}\right.$; $\left.I_{\mathrm{t}}=0.10 \mathrm{nA}\right)$, and $(\mathrm{d})$ a single $\mathrm{Er}_{3} \mathrm{~N} @ \mathrm{C}_{80}$ molecule island $\left(31 \times 24 \mathrm{~nm}^{2} ; V_{\mathrm{s}}=+2.5 \mathrm{~V} ; I_{\mathrm{t}}=0.10 \mathrm{nA}\right)$. The profile in (e) derives from image (d) beginning where the arrow is pointing. (f) A close-up STM image of a fullerene island illustrating the orbitals of individual $\mathrm{Er}_{3} \mathrm{~N} @ \mathrm{C}_{80}$ molecules $\left(7 \times 7 \mathrm{~nm}^{2} ; V_{\mathrm{s}}=+0.4 \mathrm{~V} ; I_{\mathrm{t}}=0.10 \mathrm{nA}\right)$. The fullerene coverage on the surface of image (c) is around 0.17 monolayers.

degassed through resistive heating and annealing for several hours. The template-making process begins with argon ion sputtering of the sample surfaces. Sputtering was performed for $10 \mathrm{~min}$ at a time with a VG Microtech EX03 Ion Gun System, operating at an argon gas pressure of $4.5 \times 10^{-4} \mathrm{~Pa}$ and $0.5 \mathrm{keV}$ beam energy. During sputtering, ion currents impinging on a $2 \times 5 \mathrm{~mm}^{2}$ area of the samples reached $2.4 \mu \mathrm{A}$. This was followed by subsequent annealing in UHV between 900 and $1100{ }^{\circ} \mathrm{C}$, for $30 \mathrm{~min}$. Temperature measurements were made with an optical pyrometer. The process is very sensitive to temperature variations, and the precise annealing temperature required to produce the desired pattern of nanostructures is indicated for the respective templates

in the results below. The template production technique is based on work that has evolved from the original discovery of nanostructures on $\mathrm{SrTiO}_{3}(001)$ [29, 25].

Auger electron spectroscopy (AES) indicates that the nanostructured surfaces are non-stoichiometric and rich in titanium [25]. After the template surfaces were prepared, $\mathrm{Er}_{3} \mathrm{~N} @ \mathrm{C}_{80}$ molecules were deposited onto them. Createc Knudsen cells, heated at $480{ }^{\circ} \mathrm{C}$, were used to evaporate isomerically pure $\mathrm{Er}_{3} \mathrm{~N} @ \mathrm{C}_{80}$ molecules (with $\mathrm{I}_{\mathrm{h}}$ symmetry) for 10-30 min, and 0.05-0.25 monolayer coverage was achieved for each surface. $\mathrm{Er}_{3} \mathrm{~N} @ \mathrm{C}_{80}$ was supplied by Luna Innovations, Blacksburg, VA, USA. (We have repeated this experiment using other fullerenes, including $\mathrm{C}_{60}, \mathrm{C}_{84}$, and $\mathrm{Nd} @ \mathrm{C}_{82}$, which produce similar results to those presented here.) The template patterns and molecular ordering were investigated through UHV STM at room temperature. Etched W tips were used for imaging the sample surfaces at room temperature with a bias voltage applied to the sample.

\section{Results}

The first surface used to order $\mathrm{Er}_{3} \mathrm{~N} @ \mathrm{C}_{80}$ is based on a $c(4 \times 2)$ reconstruction [30, 31] covering up to a third of the surface. The rest of the surface is covered in domains of linear nanostructures [29, 25] termed dilines. An STM image of the $c(4 \times 2)$ reconstruction with an isolated diline is shown in figure 1(b) and was formed by annealing in UHV at $1090{ }^{\circ} \mathrm{C}$ after sputtering. $\mathrm{Er}_{3} \mathrm{~N} @ \mathrm{C}_{80}$ is deposited on the $\mathrm{c}(4 \times 2)$-based template heated at $250^{\circ} \mathrm{C}$. The heating provides enough thermal energy for the fullerenes to diffuse on the surface and form monolayer islands of close packed (cp) planar assemblies on the $\mathrm{c}(4 \times 2)$ surface (figure $1(\mathrm{c}))$. The height of the fullerene islands is typically of the order of $1 \mathrm{~nm}$, while the packing separation of the fullerenes averages about $1.2 \mathrm{~nm}$, as illustrated in the STM image and profile of figures 1(d) and (e). Other experiments [32-35] using similarly sized endohedral fullerenes on various surfaces show islands with similar close-packed island geometries. An interesting feature of these cp islands is that the fullerene cages appear to be locked in orientation and location at room temperature. This is evident from figure 1(f) where the fullerene orbitals (internal structures) are imaged. The orbitals are highly complex structures and are rotated in a variety of orientations in $\mathrm{cp}$ islands [36].

Overall island orientation appears random, and island size and shape are not influenced by the crystallography of the $\mathrm{c}(4 \times$ 2) substrate. Thus, there is no epitaxial relationship between the $\mathrm{Er}_{3} \mathrm{~N} @ \mathrm{C}_{80}$ islands and the underlying $\mathrm{c}(4 \times 2)$ substrate (figure 1(c)). However, molecule-substrate interactions appear to be strong enough to freeze the motion of the molecules at room temperature, for this particular reconstruction. The fullerenes are rarely seen on the diline structures. Further, unlike many other fullerene systems $[37,34]$ the islands do not require step-edge sites for nucleation and growth; islands are typically found in the middle of $\mathrm{c}(4 \times 2)$ terraces (figure $1(\mathrm{c}))$, and may grow into step-edges.

The second template surface, shown in figure 2(a) and formed by sputtering and subsequent annealing at $930{ }^{\circ} \mathrm{C}$, includes 2D domains of linear nanostructures termed trilines [25] that appear as three protruding rows in the STM image. 


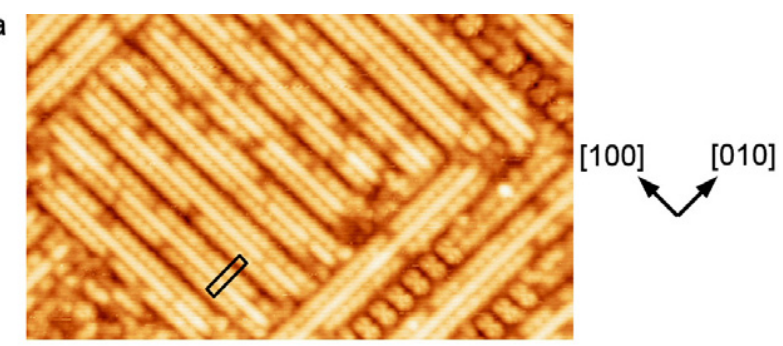

b

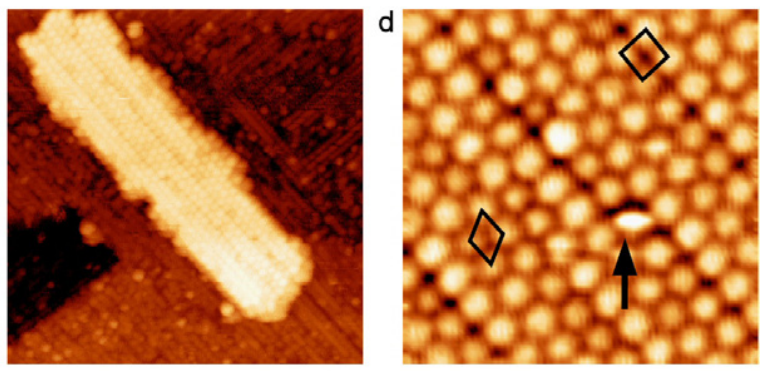

C

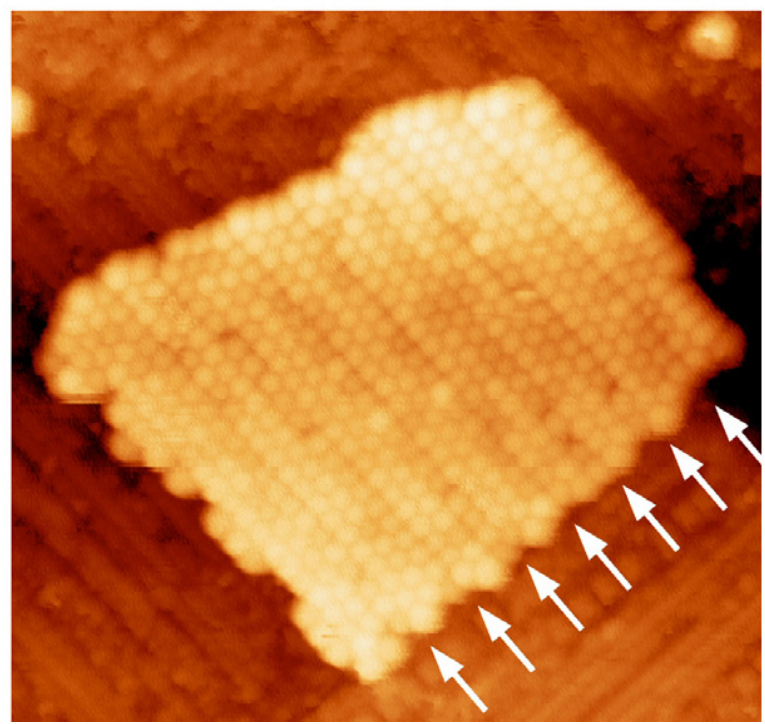

Figure 2. Epitaxial ordering on a $(9 \times 2)$ triline surface. STM images of: (a) a template with 'triline' domains forming a $(9 \times 2)$ overlayer (rectangle) $\left(40 \times 24 \mathrm{~nm}^{2} ; V_{\mathrm{s}}=+0.80 \mathrm{~V} ; I_{\mathrm{t}}=0.30 \mathrm{nA}\right)$, (b) a narrow island of fullerenes aligned and shaped by the underlying triline domain $\left(48 \times 48 \mathrm{~nm}^{2} ; V_{\mathrm{s}}=+2.0 \mathrm{~V}\right.$;

$I_{\mathrm{t}}=0.06 \mathrm{nA}$ ), (c) an island of fullerenes showing 'stripes' separated by dislocations as pointed out by the arrows $\left(42.6 \times 40.5 \mathrm{~nm}^{2}\right.$;

$\left.V_{\mathrm{s}}=+1.8 \mathrm{~V} ; I_{\mathrm{t}}=0.03 \mathrm{nA}\right)$ and (d) a high-pass-filtered close-up of a fullerene island illustrating dislocations as square-packed rows of fullerenes (square) and hexagonal packing within stripes oriented in the [100] direction (rhombus) $\left(12.4 \times 12.4 \mathrm{~nm}^{2} ; V_{\mathrm{s}}=+1.8 \mathrm{~V}\right.$; $\left.I_{\mathrm{t}}=0.03 \mathrm{nA}\right)$. A dislocation kink is pointed out by the arrow in (d). Fullerene coverage on the surface shown in image (b) is around 0.22 monolayers.

About a third of the surface was covered in triline domains. The two outer rows of trilines look identical in structure to the rows of the above-mentioned dilines, but they are separated by a 'backbone'. In close-packed form, domains of trilines display a $(9 \times 2)$ overlayer on the surface, as indicated by the rectangle in figure 2(a). $\mathrm{Er}_{3} \mathrm{~N} @ \mathrm{C}_{80}$ is deposited on surfaces partially covered in triline domains heated at $200^{\circ} \mathrm{C}$. The resultant ordering of $\mathrm{Er}_{3} \mathrm{~N} @ \mathrm{C}_{80}$ is epitaxial with islands assembling preferentially on triline domains. This is illustrated in the STM image of figure 2(b) where the size and shape of the fullerene islands are confined to the dimensions of the triline domain. Fullerene ordering is in packed rows aligned in the direction of the underlying trilines. The rows of fullerenes are grouped into stripes that are about three fullerene rows wide.

In figure 2(c) the stripes are more resolved. The white arrows point to boundaries between stripes within a fullerene island. These are phase boundaries or dislocations, and are generally defined by square-packed fullerenes (figure 2(d)). While the island is predominantly composed of $\mathrm{cp}$ fullerenes (with a base-vector oriented in the [100] crystallographic direction and a nearest neighbour separation of $1.2 \mathrm{~nm}$ ), a super-periodic arrangement of [100]-oriented dislocations interrupts the cp structure. These dislocations are typically separated by $3.5 \mathrm{~nm}$, and usually host three rows of $\mathrm{cp}$ fullerenes in between. This periodicity strongly correlates with the underlying $(9 \times 2)$ pattern, which follows a $3.51 \mathrm{~nm}$ period in the [010] direction of figure 2(c) (the lattice constant of $\mathrm{SrTiO}_{3}$ is $0.3905 \mathrm{~nm}$ ). However, a number of kinks exist in some of the dislocations found in the island of figure 2(c). Kinks shift the dislocation and increase (or decrease) the width of a stripe to four (or two) fullerenes. Wider stripes are likely to exist as a result of defective structures in the underlying template. The features found inside these fullerene islandspacking, dislocations and kinks - are highlighted in figure 2(d).

Like the $c(4 \times 2)$-based template, fullerenes on the triline domain template avoid becoming attached to areas of the surface covered in diline structures, and the molecule islands do not necessarily attach to step-edges. On the other hand, while a $\mathrm{c}(4 \times 2)$ surface allows fullerenes to close pack into freely oriented islands or rafts, a $(9 \times 2)$ surface enforces a strong, yet 'frustrated', epitaxial relationship. The periodic dislocations are means of relaxing the 'frustration' or mismatch between the molecular cp pattern and the $(9 \times 2)$ template.

One-dimensional ordering of $\mathrm{Er}_{3} \mathrm{~N} @ \mathrm{C}_{80}$ molecules into singular isolated chains is achieved on a third surface template. This template consists of isolated linear arrangements of ordered trenches (figure 3(a)), and was produced after sputtering and subsequent annealing around $980^{\circ} \mathrm{C}$. Trenches appear as nanoscale voids aligned in rows, oriented in the $\langle 100\rangle$ directions. These dark voids are at least $0.2 \mathrm{~nm}$ deep and are separated by cross-like features, as shown in figure 3(a). $\mathrm{Er}_{3} \mathrm{~N} @ \mathrm{C}_{80}$ molecules order on samples heated at $170-200^{\circ} \mathrm{C}$ during deposition. Fullerenes assemble uniformly into 1D chains within the trenches, as illustrated in the STM image of figure 3(b). The height of the fullerene chains in relation to the surrounding substrate is typically $0.8 \mathrm{~nm}$. This is noticeably less than the $1 \mathrm{~nm}$ height of the molecule islands formed using the first two templates mentioned here (figures 1 and 2), and suggests that the fullerenes sit within the trenches.

The molecules mostly assemble into pairs, or occasionally triplets, within a chain. The close-up inset (figure 3(c)) demonstrates the pairing in a six-unit chain. This configuration coincides with the topology of the trench structures, and not the topology of the surrounding substrate. Pairs are close-packed with a $1.2 \mathrm{~nm}$ separation between fullerene centres, whereas adjacent fullerenes between pairs have a $1.9 \mathrm{~nm}$ centre-tocentre separation (figure 3(c)). This forms a $3.1 \mathrm{~nm}$ periodicity ( 8 unit cells of $\mathrm{SrTiO}_{3}$ ) along a chain. Chain lengths are limited only by the length of the trench array, or the supply of fullerenes. 

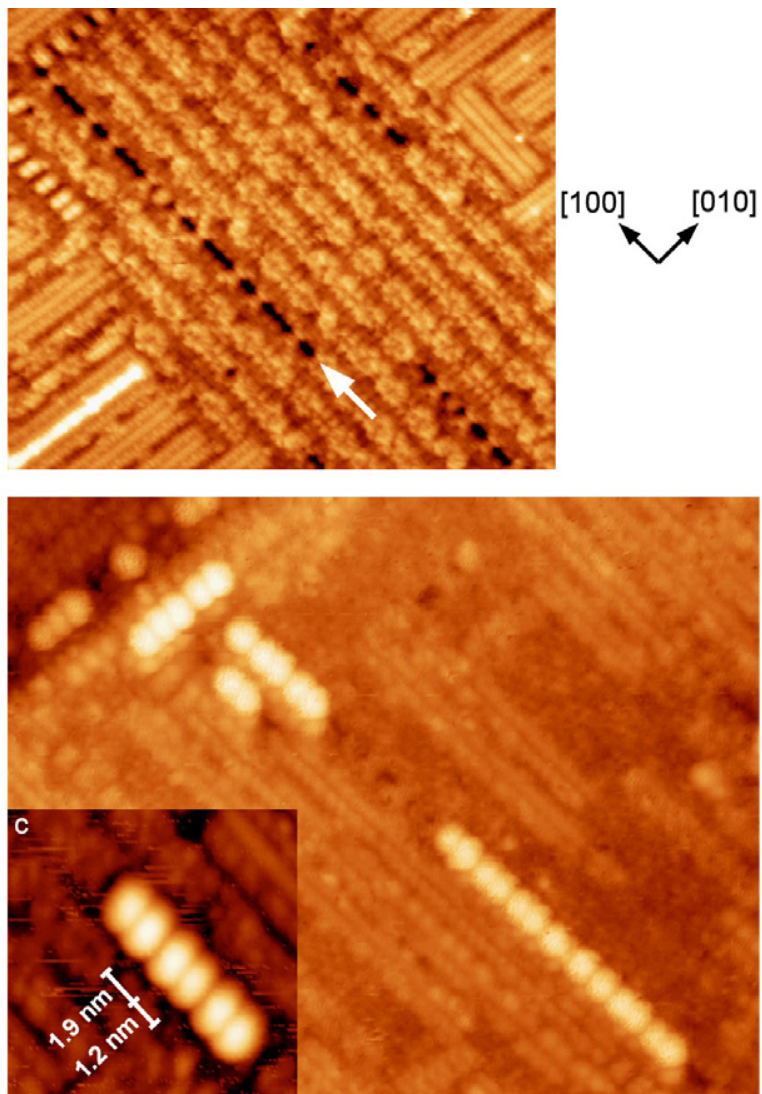

Figure 3. One-dimensional chain ordering in trenches. STM images of (a) the third template pattern which hosts 'trench' structures, one of which is indicated by the arrow $\left(41 \times 33 \mathrm{~nm}^{2} ; V_{\mathrm{s}}=+1.0 \mathrm{~V}\right.$; $I_{\mathrm{t}}=0.30 \mathrm{nA}$ ), (b) fullerene molecules assembled into 1D singular chains sitting in the trenches $\left(43.8 \times 33.8 \mathrm{~nm}^{2} ; V_{\mathrm{s}}=+2.0 \mathrm{~V}\right.$; $I_{\mathrm{t}}=0.10 \mathrm{nA}$ ) and (c) a high resolution illustration of fullerene pairing in the chains $\left(12.4 \times 12.4 \mathrm{~nm}^{2} ; V_{\mathrm{s}}=+1.5 \mathrm{~V} ; I_{\mathrm{t}}=0.10 \mathrm{nA}\right)$. Fullerene coverage on the surface shown in image (b) is around 0.08 monolayers.

A fourth template shown in figure 4(a) is a surface hosting highly ordered 2D arrays of trenches which cover around a sixth of the surface, and can be formed after sputtering and subsequent repeated annealing $(>1 \mathrm{~h})$ near $945^{\circ} \mathrm{C}$. These trench arrays, termed waffles, have an associated $(8 \times 6)$ surface periodicity. Following the same molecular deposition procedure as for the third template, waffle structures can be decorated with $\mathrm{Er}_{3} \mathrm{~N} @ \mathrm{C}_{80}$ as shown in figure 4(b). Fullerenes preferentially fill up the trenches and waffles before settling on other regions of the surface (e.g. step-edges). Pairs of fullerenes are all aligned in the same [010] direction, and are spatially arranged in a repeated rectangular fashion with a $3.10 \times 2.35 \pm 0.05 \mathrm{~nm}^{2}$ unit cell. This directly corresponds to the $(8 \times 6)$ periodicity of the underlying waffles.

The $2 \mathrm{D}$ ordering extends over distances limited only by the size of the waffle domains. These arrays are more uniform and exhibit stronger periodicity than many of the 1D chains formed on the third template described in figure 3. Moleculesurface interactions influence the ordering more than the other template patterns considered above. Fullerenes can be displaced by the STM tip at low imaging bias of $\sim 0.5 \mathrm{~V}$ (i.e. when the tip is very close to the sample). The $\mathrm{C}_{80}$ cage of

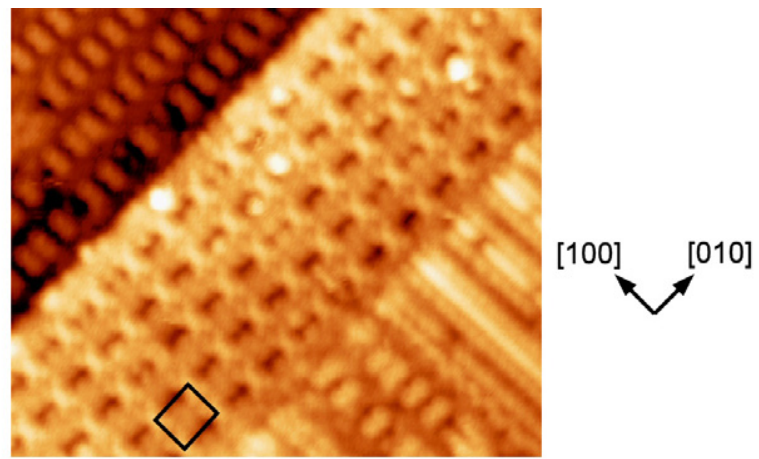

b

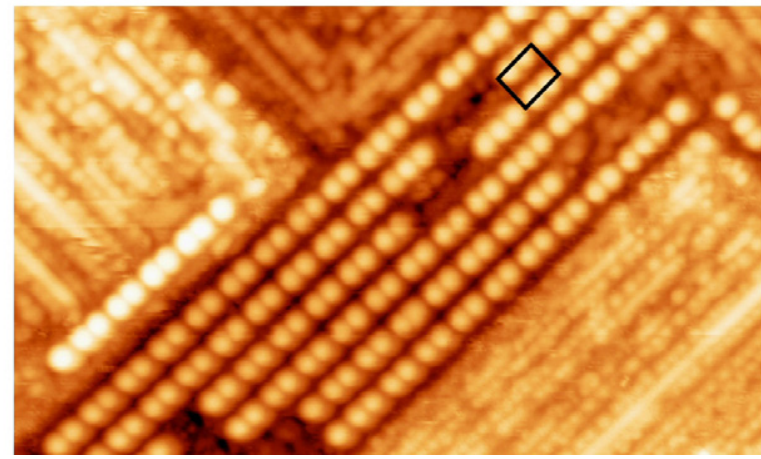

Figure 4. Two-dimensional grid ordering on a $(8 \times 6)$ waffle surface STM images of: $(a)$ the 'waffle' $(8 \times 6)$ surface and $(b)$ a self-organized 2D fullerene array in direct coordination to the topology of the waffle template. Imaging parameters:

(a) $31 \times 16 \mathrm{~nm}^{2} ; V_{\mathrm{s}}=+1.5 \mathrm{~V} ; I_{\mathrm{t}}=0.1 \mathrm{nA}$ and (b) $50 \times 30 \mathrm{~nm}^{2}$; $V_{\mathrm{s}}=+3.0 \mathrm{~V} ; I_{\mathrm{t}}=0.1 \mathrm{nA}$. Fullerene coverage on the surface shown in image (b) is around 0.15 monolayers.

$\mathrm{Er}_{3} \mathrm{~N} @ \mathrm{C}_{80}$ is inert and resists covalent bonding [16-18]. The pairing of the fullerenes in the waffle structure can therefore be attributed to the topographic constraints of the substrate, and is not due to covalent bonding between adjacent fullerenes.

\section{Discussion}

The way in which these molecules order on $\mathrm{SrTiO}_{3}(001)$ is determined by competing molecule-molecule interactions and molecule-substrate interactions. Molecule-molecule interactions of these fullerenes are thought to be based on van der Waals bonding $[16,18,33]$, and the nature of this bond is likely to be the same for all the ordering patterns demonstrated above. However, the interaction of the molecules with the different templates varies significantly, because the difference in topography and chemical structure of the templates gives rise to changes in the molecule-substrate bond strengths. The vast majority of fullerenes desorb without decomposition from the nanostructured surfaces if the samples are annealed at temperatures over $600^{\circ} \mathrm{C}$. This indicates that the bonds between the substrate and the fullerenes are either strong van der Waals or weakly/intermediately ionic [38-40].

On the $\mathrm{c}(4 \times 2)$ template (figure 1$)$, the surface topographic features are comparatively flat, and the fullerene islands do not grow epitaxially. Hence, the molecular binding sites on the $c(4 \times 2)$ reconstruction cannot be related to particular atomic locations of the substrate. The lack of site coordination is a further indication that the nature of the bonds is van der Waals 
or possibly weakly ionic [38-40]. Rotational and translational motion of the fullerenes within islands does not occur on the $c(4 \times 2)$ surface, but is observed at room temperature on other surfaces such as Ag-terminated $\mathrm{Si}(111)$. This implies strong (but not covalent) bonding between the fullerenes and the $\mathrm{c}(4 \times 2)$ substrate $[33,41,36]$.

The $(9 \times 2)$ triline surface (figure 2$)$ causes epitaxial ordering of fullerenes and induces regularly spaced dislocations within islands. It is most probable that the epitaxy is due to the chemical nature of the triline backbone, which acts as a preferential bonding site for the fullerenes. Maximum bonding between the fullerenes and the backbone is achieved when one of the close-packed directions of the fullerene islands is aligned with the backbones. Evaporation of the fullerenes from all of the templates at around $600{ }^{\circ} \mathrm{C}$ leaves no carbon residue which means that the bonding is van der Waals or ionic. Fullerene adsorption on anisotropic metal surfaces can also produce superperiodic ordering [42-48]. The underlying metal surfaces typically reconstruct upon molecular adsorption, whereas this does not appear to happen on the nanostructured $\mathrm{SrTiO}_{3}(001)$ surface.

The third and fourth surface templates feature trenches arranged in single lines and 2D arrays, respectively. Figure 3 shows three trenches of different lengths, which contain irregularly positioned crosses along their lengths. The dimensions of the trenches $(\sim 0.2 \mathrm{~nm}$ depth, $\sim 1.0 \mathrm{~nm}$ width $)$ are well suited for adsorption of fullerenes within them. The area for bonding of a fullerene will be greatest within the trench, and they consequently act as preferential bonding sites compared to their surroundings. When the trenches in figure 3 form domains, the crosses become regularly spaced and align with each other across trenches, forming waffle structures (figure 4). The adsorption of fullerenes into the waffle is the same as for the trenches. However, the crosses in the waffle structure are aligned, which gives rise to highly ordered fullerene grids as shown in figure 4(b). The ordering of the crosses in figure 4(a) along the [010] direction is $\sim 3.1 \mathrm{~nm}$ (eight unit cells). On occasion we also see larger separations between the crosses, and in these circumstances more than two fullerenes may fit in the gap. This can be seen in figure 4(b) where most of the fullerenes appear as pairs, but four fullerene triplets can also be seen. Surface topography strongly dictates the fullerene assembly process in trenches and waffles: closepacked island formation is completely inhibited. The nature of the ordering may also indicate anisotropic diffusion during the deposition/sample heating process, and can be compared to adatom diffusion mechanisms [49]. For example, fullerenes are likely to diffuse along the length of trenches with less energy than is required to diffuse between adjacent trench lines in a waffle.

\section{Conclusion}

To summarize, non-stoichiometric nanostructured $\mathrm{SrTiO}_{3}(001)$ surfaces have been employed as a template to self-assemble $\mathrm{Er}_{3} \mathrm{~N} @ \mathrm{C}_{80}$ molecules into four distinctive configurations. By tuning the annealing conditions, different template patterns can be formed. By selecting the template pattern, $\mathrm{Er}_{3} \mathrm{~N} @ \mathrm{C}_{80}$ molecules can be made to assemble into particular configurations corresponding to the underlying template pattern. Frustrated epitaxial and non-epitaxial close-packed fullerene island assembly has been achieved. In addition, certain template patterns allow single 1D chains, as well as open structured, 2D grid arrays of paired fullerenes, to form. Each type of ordering has its merits for potential use in a variety of molecular technologies, ranging from multilayered Coulomb blockade devices [50] using the close-packed islands to spin/photon activated molecular wires using the 1D fullerene chains. Given the high- $\kappa$ substrate properties of $\mathrm{SrTiO}_{3}$, the robust molecular ordering, non-covalent molecule-substrate bonding and suitable spatial dimensions, there is clear potential for using the $(8 \times 6)$ waffle-based arrangement as a platform for developing cellular automata networks, particularly for QIP. This method of template-assisted assembly can be applied for a wide variety of fullerenes.

\section{Acknowledgments}

The authors thank the Royal Society, the EPSRC, and JEOL UK for funding, and Chris Spencer (JEOL UK) for valuable technical support.

\section{References}

[1] Petruska M A, Malko A V, Voyles P M and Klimov V I 2003 High-performance, quantum dot nanocomposites for nonlinear optical and optical gain applications Adv. Mater. 15 610-3

[2] Eremtchenko M, Schaefer J A and Tautz F S 2003 Understanding and tuning the epitaxy of large aromatic adsorbates by molecular design Nature $\mathbf{4 2 5} 602-5$

[3] Parviz B A, Ryan D and Whitesides G M 2003 Using self-assembly for the fabrication of nano-scale electronic and photonic devices IEEE Trans. Adv. Packaging 26 233-41

[4] Cheng J Y, Mayes A M and Ross C A 2004 Nanostructure engineering by templated self-assembly of block copolymers Nat. Mater. 3 823-8

[5] Heinrich A J, Lutz C P, Gupta J A and Eigler D M 2002 Molecule cascades Science 298 1381-7

[6] Champagne A R, Abhay N P and Ralph D C 2005 Mechanically adjustable and electrically gated single-molecule transistors Nano Lett. 5 305-8

[7] Nielsen M A and Chuang I L 2000 Quantum Computation and Quantum Information (Cambridge: Cambridge University Press)

[8] Bethune D S, Johnson R D, Salem J R, Devries M S and Yannoni C S 1993 Atoms in carbon cages: the structure and properties of endohedral fullerenes Nature 366 123-8

[9] Shinohara H 2000 Endohedral metallofullerenes Rep. Prog. Phys. 63 843-92

[10] Benjamin S C 2002 Quantum computing without local control of qubit-qubit interactions Phys. Rev. Lett. 88017904

[11] Benjamin S C and Bose S 2003 Quantum computing with an always-on Heisenberg interaction Phys. Rev. Lett. 90247901

[12] Harneit W 2002 Fullerene-based electron-spin quantum computer Phys. Rev. A 65032322

[13] Twamley J 2003 Quantum-cellular-automata quantum computing with endohedral fullerenes Phys. Rev. A 67052318

[14] Balzani V, Credi A and Venturi M 2003 Molecular logic circuits ChemPhysChem 4 49-59

[15] Hiroshiba N, Tanigaki K, Kumashiro R, Ohashi H, Wakahara T and Akasaka T $2004 \mathrm{C}_{60}$ field effect transistor with electrodes modified by La $@ \mathrm{C}_{82}$ Chem. Phys. Lett. $400235-8$

[16] Stevenson S et al 1999 Small-bandgap endohedral metallofullerenes in high yield and purity Nature $40155-7$ 
[17] Kobayashi K, Sano Y and Nagase S 2001 Theoretical study of endohedral metallofullerenes: $\mathrm{Sc}_{3-n} \mathrm{La}_{n} \mathrm{~N} @ \mathrm{C}_{80}(n=03)$ J. Comput. Chem. 22 1353-8

[18] Olmstead M M, Bettencourt-Dias A d, Duchamp J C, Stevenson S, Dorn H C and Balch A L 2000 Isolation and crystallographic characterization of $\mathrm{ErSc}_{2} \mathrm{~N} @ \mathrm{C}_{80}$ : an endohedral fullerene which crystallizes with remarkable internal order J. Am. Chem. Soc. 122 12220-6

[19] Macfarlane R M, Bethune D S, Stevenson S and Dorn H C 2001 Fluorescence spectroscopy and emission lifetimes of $\mathrm{Er}^{3+}$ in $\mathrm{Er}_{x} \mathrm{Sc}_{3-x} \mathrm{~N} @ \mathrm{C}_{80}(x=1-3)$ Chem. Phys. Lett. 343 229-34

[20] Petrosyan D and Kurizki G 2002 Scalable solid-state quantum processor using subradiant two-atom states Phys. Rev. Lett. 89207902

[21] Theobald J A, Oxtoby N S, Phillips M A, Champness N R and Beton P H 2003 Controlling molecular depostion and layer structure with supramolecular surface assemblies Nature 424 1029-31

[22] Corso M, Auwarter W, Muntwiler M, Tamai A, Greber T and Osterwalder J 2004 Boron nitride nanomesh Science 303 217-20

[23] Stepanow S, Lingenfelder M, Dmitriev A, Spillmann H, Delvigne E, Lin N, Deng X, Cai C, Barth J V and Kern K 2004 Steering molecular organization and host-guest interactions using two-dimensional nanoporous coordination systems Nat. Mater. 3 229-33

[24] Bonifazi D, Spillmann H, Kiebele A, de Wild M, Seiler P, Cheng F, Güntherodt H J, Jung T and Diederich F 2004 Supramolecular patterned surfaces driven by cooperative assembly of $\mathrm{C}_{60}$ and porphyrins on metal substrates Angew. Chem. Int. Edn 43 4759-63

[25] Deak D S, Silly F, Newell D T and Castell M R 2006 Ordering of $\mathrm{TiO}_{2}$-based nanostructures on $\mathrm{SrTiO}_{3}(001)$ surfaces J. Phys. Chem. B 110 9246-51

[26] Javey A, Kim H, Brink M, Wang Q, Ural A, Guo J, Mcintyre P, McEuen P, Lundstrom M and Dai H 2002 High- $\kappa$ dielectrics for advanced carbon-nanotube transistors and logic gates Nat. Mater. 1 241-6

[27] Kim B M, Brintlinger T, Cobas E, Fuhrer M S, Zheng H, Yu Z, Droopad R, Ramdani J and Eisenbeiser K 2004 High-performance carbon nanotube transistors on $\mathrm{SrTiO}_{3} / \mathrm{Si}$ substrates Appl. Phys. Lett. 84 1946-8

[28] Javey A, Tu R, Farmer D B, Guo J, Gordon R G and Dai H 2005 High performance n-type carbon nanotube field-effect transistors with chemically doped contacts Nano Lett. 5 345-8

[29] Castell M R 2002 Nanostructures on the $\mathrm{SrTiO}_{3}(001)$ surface studied by STM Surf. Sci. 516 33-42

[30] Castell M R 2002 Scanning tunneling microscopy of reconstructions on the $\mathrm{SrTiO}_{3}(001)$ surface Surf. Sci. 505 $1-13$

[31] Erdman N, Warschkow O, Asta M, Poeppelmeier K R, Ellis D E and Marks L D 2003 Surface structures of $\mathrm{SrTiO}_{3}$ (001): $\mathrm{A} \mathrm{TiO}_{2}$-rich reconstruction with a $\mathrm{c}(4 \times 2)$ unit cell J. Am. Chem. Soc. 124 10050-6

[32] Wang L et al 2004 Morphology, structure, and electronic properties of $\mathrm{Ce} @ \mathrm{C}_{82}$ films on $\mathrm{Ag}: \mathrm{Si}(111)-(\sqrt{3} \times \sqrt{3}) \mathrm{R} 30^{\circ}$ Surf. Sci. 564 156-64

[33] Fujiki S, Kubozono Y, Rikiishi Y and Urisu T 2004 Scanning tunneling microscopy/spectroscopy studies of two isomers of $\mathrm{Ce} @ \mathrm{C}_{82}$ on $\mathrm{Si}(111)-(7 \times 7)$ surface Phys. Rev. B 70235421
[34] Shi B R, Wang X S, Huang H, Yang S H, Heiland W and Cue N 2001 Scanning tunneling microscopy of endohedral metallofullerene $\mathrm{Tb} @ \mathrm{C}_{82}$ on $\mathrm{C}_{60}$ film and Si100 $2 \times 1$ surface J. Phys. Chem. B $10511414-8$

[35] Lin N, Ding J Q, Yang S H and Cue N 1996 STM investigation of metal endohedral fullerene adsorbed on a Van der Waals surface Phys. Lett. A 222 190-4

[36] Leigh D F, Owen J H G, Lee S M, Porfyrakis K, Ardavan A, Dennis T J S, Pettifor D G and Briggs G A D 2005 Distinguishing two isomers of $\mathrm{Nd} @ \mathrm{C}_{82}$ by scanning tunneling microscopy and density functional theory Chem. Phys. Lett. 414 307-10

[37] Tamai A, Auwärter W, Cepek C, Baumberger F, Greber T and Osterwalder J 2004 One-dimensional chains of $\mathrm{C}_{60}$ molecules on $\mathrm{Cu}$ (221) Surf. Sci. 566-568 633-7

[38] Modesti S, Cerasari S and Rudolf P 1993 Determination of charge states of $\mathrm{C}_{60}$ adsorbed on metal surfaces Phys. Rev. Lett. 71 2469-72

[39] Goldoni A and Paolucci G 1999 The interaction of $\mathrm{C}_{60}$ with $\mathrm{Ag}(100)$ : strong predominantly ionic bonding Surf. Sci. 437 353-61

[40] Suto S, Sakamoto K, Kondo D, Wakita T, Kimura A and Kakizaki A 1999 Bonding nature of $\mathrm{C}_{60}$ adsorbed on $\operatorname{Si}(111) 7 \times 7$ and $\operatorname{Si}(100) 2 \times 1$ surfaces studied by HREELS and PES Surf. Sci. 427/428 85-90

[41] Gimzewski J K, Reihl B, Schlittler R R and Tschudy M 1994 Internal structure of $\mathrm{C}_{60}$ on $\mathrm{Au}(110)$ as observed by low-temperature scanning tunneling microscopy J. Vac. Sci. Technol. B 12 2153-5

[42] Pedio M, Felici R, Torrelles X, Rudolf P, Capozi M, Rius J and Ferrer S 2000 Study of $\mathrm{C}_{60} / \mathrm{Au}(11)-p(6 \times 5)$ reconstruction from in-plane x-ray diffraction data Phys. Rev. Lett. 85 1040-3

[43] Gimzewski J K, Modesti S and Schlittler R R 1994 Cooperative self-assembly of $\mathrm{Au}$ atoms and $\mathrm{C}_{60}$ on $\mathrm{Au}(110)$ surfaces Phys. Rev. Lett. 72 1036-9

[44] Modesti S, Gimzewski J K and Schlittler R R 1995 Stable and metastable reconstructions at the $\mathrm{C}_{60} / \mathrm{Au}(110)$ interface Surf. Sci. 331-333 1129-35

[45] Weckesser J, Cepek C, Fasel R, Barth J V, Baumberger F, Greber T and Kern K 2001 Binding and ordering of $\mathrm{C}_{60}$ on $\mathrm{Pd}(110)$ : investigations at the mesoscopic scale J. Chem. Phys. 115 9001-9

[46] David T, Gimzewski J K, Purdie D, Reihl B and Schlittler R R 1994 Epitaxial growth of $\mathrm{C}_{60}$ on $\mathrm{Ag}(110)$ studied by scanning tunneling microscopy and tunneling spectroscopy Phys. Rev. B 50 5810-3

[47] Murray P W, Pedersen M O, Laegsgaard E, Stensgaard I and Besenbacher F 1997 Growth of $\mathrm{C}_{60}$ on $\mathrm{Cu}(110)$ and $\mathrm{Ni}(110)$ surfaces: $\mathrm{C}_{60}$-induced interfacial roughening Phys. Rev. B 55 9360-3

[48] Felici R, Pedio M, Borgatti F, Iannotta S, Capozi M, Ciullo G and Stierle A 2005 X-ray-diffraction characterization of $\mathrm{Pt}(111)$ surface nanopatterning induced by $\mathrm{C}_{60}$ adsorption Nat. Mater. 4 688-92

[49] Zhang Z and Lagally M G 1997 Atomistic processes in the early stages of thin-film growth Science 276 377-83

[50] Wakayama Y, Kubota T, Suzuki H, Kamikado T and Mashiko S 2003 Molecular Coulomb islands for single-electron tunneling in $\mathrm{SiO}_{2} /$ molecular layer/SiO multilayers on Si(100) J. Appl. Phys. 94 4711-3 